\title{
PROCEEDINGS OF THE MEETING OF THE NORTH CENTRAL SECTION OF THE AMERICAN PSYCHOLOGICAL ASSOCIATION.
}

\section{REPORT OF THE SRcritary.}

A meeting of the North Central Section of the American Psychological Association was held at the University of Chicago, April 22, 1905. About forty-five persons attended the meeting. The following papers, presented by members of the association and others, were read and discussed:

Abstracts of Paphrs.

The Perception of Reality. J. D. SToops.

Perception is the apprehension of a particular thing immediately present in experience. But because this particular thing is perceived as what it is, there is a 'fringe' about it, an ideal linkage which connects the particular with other things of its kind. If this ideal element, the relation, is abstracted and generalized, so that it is independent of the particular, we have a concept; if it is a 'fringe' about some definite concrete particular, we have a percept. In the process of perception we do not transcend experience. But when we conceive things, when we know things, do we not transcend experience? James says that we do not. Ideas are secondary, are dependent upon experience, and lead only to percepts. They never represent things beyond experience. Ideas stand therefore not between the mind and things external to the mind. They stand for some experience beyond immediate perceptual experience.

But if this be the true view, are we not driven to say that reality is only what we experience? It seems not. So far as this view goes, it leaves untouched the problem of the nature of things, in so far as they are not experienced.

The Trradiation of Light. Fostrn P. Boswerx.

There are various modifications in the form of a small moving luminous image which are probably due to the presence of one form or another of visual irradiation.

There are five varieties of irradiation which may be conveniently distinguished but which are all capable of being brought under a single principle of explanation - the dissemination of neural excitation over the retina. 
Irradiation a. - A very rapid spreading of the excitation over the retina, extending far beyond the borders of the stimulated portion and occurring immediately upon the impact of the stimulating light.

Irradiation $\beta_{.}$- Irradiation within the stimulated portion of the retina after the form of a figure becomes distinctly perceptible.

Irradiation $\gamma$. - Emanations of decreasing intensity extend themselves outward and backward from a moving image until lost in the darkness of the background.

Irradiation 8. - The well known form of irradiation which occurs when a surface of greater intensity enlarges itself at the expense of one of less intensity.

Irradiation e.-A form having many of the characteristics of Irradiation $a$ but occurring only after long periods of stimulation, 30 seconds to a minute or more.

Report on Recent Work on the Growth of the Nervous System.

Henry H. Donaldoson.

The Wundt Pendulum Complication Apparatus as Tested by the Duddell Oscillograph. Wastra Dill Scotr.

The Duddell oscillograph records times with perfect accuracy to less than a thousandth of a second. The Wundt pendulum complication apparatus contains within itself no device for testing its own accuracy, and many users of the instrument have felt themselves forced to abandon it. The instrument can be tested with perfect accuracy by means of the Duddell oscillograph. By such a test the instrument in the psychological laboratory of Northwestern University has been found to be subject to a constant determinable error. When the bell is adjusted to give the clearest ring and when the bell tap comes at the slowest movement of the hand the error is 27 thousandths of a second and is always negative.

Pragmatism and its Critics. Adorson W. Moorl.

(This paper will be published in full in the May number of the Philosophical Review.)

Development of Ethical Sentiment in the Child. M. V. O'Srren.

The infant reveals no true feeling of duty, no sense of 'the ought' in his conduct. Whatever action will bring him food and relief from distress is right, and may be freely performed. He shows no tendency toward self-restraint for the good of others in any of his activities. But by the twelfth week, perhaps, one may note the beginnings of the sense of a personal environment to be reckoned with. Before the completion of the first year the child will of his own volition restrain himself in his crying, teasing, bullying, appropriating the possessions 
of his trothers and sisters, etc. He will also share his possessions with others. Ethical development thereafter, in all normal cases, is a long story of continually increasing self-restraint in certain social situations, and helpfulness in others.

The genesis of the child's self-restraint is found in his discovery that certain acts turn out ill for him; the social environment will not tolerate them. In a similar way he discovers that it pays to be helpful and generous. Social censure and approval are thus at the bottom of his ethical discriminations. But direct imitation reinforces tremendously the penalties and rewards administered by the social environment.

Until the inhibition or performance of an action becomes facile, so that it will occur more or less mechanically, there will always be something of a struggle between impulsions and restraining or importuning ideals of social origin, and this is felt as strain or tension, which we call the sense of duty in its simplest, crudest form. Actions at first must, then later ought to be performed.

Personal forces which in the beginning function in the child's consciousness focally and individually, come in the course of development to function subconsciously and coalescently. It may happen that all traces of concrete personal presence will disappear from consciousness; but this will not occur until conduct in any particular situation is so definitely established that to depart therefrom would occasion distress. Conscience arises slowly when social ideals begin to repress, modify, supplant impulsions; and it subsides when this work is thoroughly accomplished.

Feeling as Emotion and Sentiment: A Neglected Chapter in Psychoiogy. Lous C. Monin.

The Upper Limit of Hearing as Affected by Differences in Age and Sex. Frank G. Bruner.

This paper presents some data on the upper limit of audibility as a result of tests made on several hundred Americans, varying in age from six to sixty-five years. These tests were made by the author, with the coöperation of Dr. R. S. Woodworth, at the Louisiana Purchase Exposition. The Edelmann type of Galton whistle was used in the tests, and afterward the pitch values of the various whistle lengths were carefully determined by objective methods.

Contrary to the results of Dr. Chas. H. Myer's tests on the Scottish children, some of the individuals tested were found to hear tones whose pitch values were upward of $40,000 \mathrm{v}$. s., and at least 50 per cent. of all whites hear tones as high as $31,000 \mathrm{v}$. s. The highest 
tones are heard by those from 15 to 25 years of age. After this the upper range of hearing gradually declines, till at $6_{5}$ years the average person hears with difficulty tones of $19,000 \mathrm{v}$. $s$.

Women on the whole have a greater range than men. In the earlier years this difference amounts at least to 2,000 ₹. 8 .

The Nature of Consistency. GuY A. TAwnex.

Consistency was defined as (I) man's immediate sense of the selfmaintaining quality of certain personal activities or (2) as the self-maintaining quality of these activities, the self-maintained being the social egoalter self of reflection. Inconsistency, correspondingly, is the felt impossibility of reacting to a situation in self-maintaining ways. From this point of view the paper attempts to show that all criteria of value may be defined in terms of consistency and that the sense of consistency is simply one factor in the reflective type of consciousness, a contribution of reflection to the cognitive experience of the race. Types of consistency rest upon the three arcs of the psycho-physical process, viz., the arc of sensation, the arc of need, and the arc of movement or the production of change in the time and space order. Types of consistency are called presentative, practical and purposive. Presentative consistency is mechanical in form, the consistency of the merely presented data of judgments of value, a postulated consistency which is always constitutive in the world. Practical consistency is defined as that of voluntarily produced changes in the body or in other objects through the body. Purposive consistency is distinguished from the purposiveness of all consistency and indeed of all mental processes in being a reflective consciousness of the relation of means to ends. Three forms of this type appear in the harmony between objects and the mind's powers of apprehension, the harmony between an object and some end external to the object, and the harmony of the object with itself - beauty, utility and perfection.

Willard C. Gorm, Acting Secretary. 